\title{
Studi kapasitas beban pencemaran sungai berdasarkan parameter organik (BOD, COD dan TSS) di Batang Lembang Kota Solok, Provinsi Sumatera Barat
}

\author{
A. Azhar ${ }^{1}$, I. Dewata ${ }^{2 *}$ \\ 1Peneliti Fungsional, Badan Penelitian dan Pengembangan Daerah Sumatera Barat, Sumatera Barat, \\ Indonesia \\ 2Program Pascasarjana Ilmu Lingkungan, UNP, Padang, Sumatera Barat, Indonesia
}

\begin{abstract}
Abstrak.
Kota Solok merupakan salah satu kota yang berada di Provinsi Sumatera Barat yang dialiri oleh sungai yang bernama sungai Batang Lembang. Pertumbuhan penduduk dan meningkatnya pengunaan sungai Batang Lembang berdampak pada daya dukung lingkungan sungai. Untuk dapat menjaga kualitas air sungai diperlukan kajian daya tampung air sungai. Lokasi penelitian ini adalah air Sungai Batang Lembang segmen Kota Solok yang melintasi Kecamatan Lubuk Sikarah dan Kecamatan Tanjung Harapan, sedangkan parameter kunci pencemaran air ialah TSS, BOD, dan COD. Parameter kualitas air Sungai Batang Lembang mengacu pada Peraturan Pemerintah Nomor 82 Tahun 2001 tentang Pengendalian Kualitas air dan Pengelolaan Pencemaran Air. Penetapan daya tampung beban pencemaran mengaplikasikan Qual2Kw. Hasil penelitian daya tampung terhadap beban pencemaran Sungai Batang Lembang Sungai kota Solok untuk parameter TSS beban maksimum harus dikurangi sebesar $28,490.00 \mathrm{~kg} / \mathrm{hari}$ dan minimum $1,425.60 \mathrm{Kg} / \mathrm{hari}, \mathrm{BOD}$ sebesar $336.96 \mathrm{Kg} /$ hari dan minimum $77.76 \mathrm{Kg} / \mathrm{hari}$ dan COD sebesar 16,264.80 Kg/hari dan minimum 3,039.12 $\mathrm{Kg} /$ hari agar kualitas air sungai dapat terjaga dengan baik. Selanjutnya diperlukan pembatasan izin serta kebijakan oleh pemerintah pada beberapa ruas tertentu agar mutu dan kualitas sungai dapat dipertahankan.
\end{abstract}

\begin{abstract}
.
Solok city is one of the city in West Sumatera Province flowed by river Batang Lembang. Population growth and increasing use of river will affect the environmental carrying capacity of river, in order to maintain quality of river water it is necessary to study carrying capacity of the river. The location of this research is Batang Lembang water segment that crosses Solok District of Lubuk Sikarah and Tanjung Harapan, while the key parameters of water pollution are TSS, BOD and COD. Water quality parameter of Batang Lembang River refers to Government Regulation Number 82 Year 2001 regarding Water Quality Control and Water Pollution Management. Determination of the pollution load capacity refers to Qual $2 \mathrm{Kw}$. The results of pollution load capacity of Batang Lembang River Solok were TSS load should be reduced by 28,490.00 kg/day (maximum) and $1,425.60 \mathrm{~kg} /$ day (minimum), BOD of $336.96 \mathrm{Kg} /$ day (maximum) and $77.76 \mathrm{Kg} /$ day (minimum), and COD of $16,264.80 \mathrm{~kg} /$ day (maximum) and 3,039.12 Kg/day (minimum) in order to maintain water quality. Furthermore necessary restrictions on permissions and policies by the government on certain stretches of river should be implemented so that the quality can be maintained.
\end{abstract}

Keywords: water quality assessment

Kata kunci: penilaian kualitas air

\section{PENDAHULUAN}

Kota Solok merupakan salah satu kota yang berada di Provinsi Sumatera Barat yang di aliri oleh Sungai Batang Lembang. Sungai ini mengalir di 2 (dua) wilayah kecamatan, yaitu (1) Kecamatan Lubuk Sikarah dan (2) Kecamatan Tanjung Harapan. Di Kecamatan Lubuk Sikarah terdapat 6 (enam) kelurahan yang dialiri Sungai Batang Lembang, yakni (1) Kelurahan Aro IV Korong, (2) IX Korong, (3) KTK, (4) Sinapa Piliang, (5) Tanah Garam, dan (6) VI Suku. Kelurahan yang dialiri Sungai Batang Lembang di wilayah Kecamatan Tanjung

\footnotetext{
* Korespondensi Penulis

Email : i_dewata@yahoo.com
} 
Harapan sebanyak 3 (tiga) kelurahan yakni (1) Kelurahan Kampung Jawa, (2) Koto Panjang dan (3) Nan Balimo. Dengan demikian, terdapat 9 (sembilan) kelurahan yang dialiri Sungai Batang Lembang segmen Kota Solok.

Sungai Batang Lembang mendapat tekanan cukup tinggi, baik oleh kegiatan domestik, industri, pertanian maupun aktivitas lainnya seperti peningkatan jumlah penduduk. Dampak yang berasal dari aktivitas manusia sangat dominan mempengaruhi kualitas Sungai Batang Lembang. Keadaan yang demikian sudah barang tentu akan berdampak pada daya dukung lingkungan, khususnya Sungai Batang Lembang dalam hal daya tampung terhadap beban pencemarannya. Untuk menjaga kualitas air Sungai Batang Lembang agar tidak mengalami penurunan pada masa mendatang, diperlukan sebuah penelitian kualitas air sungai pada kondisi eksisting. Penelitian kualitas air sungai yang dimaksud adalah penentuan kapasitas daya tampung dalam menerima limbah cair yang masuk.

\subsection{Parameter kunci pencemaran air}

Parameter kualitas air sungai yang diteliti ialah Total Suspeded Solid (TSS), Biological Oxygen Demand (BOD), dan Chemical Oxygen Demand (COD). TSS adalah padatan yang menyebabkan kekeruhan air, tidak terlarut dan tidak dapat langsung mengendap. Padatan tersuspensi akan dapat mengurangi penetrasi cahaya matahari ke dalam air, sehingga akan mempengaruhi regenerasi oksigen dan fotosintesis (Kristanto 2002).

BOD merupakan salah satu parameter indikator pencemar di dalam air yang disebabkan oleh limbah organik. BOD adalah oksigen yang dibutuhkan untuk mengoksidasi bahan organik oleh mikroorganisme aerobik sehingga menjadi bentuk anorganik yang stabil. Keberadaannya di lingkungan sangat ditentukan oleh limbah organik, baik yang berasal dari limbah rumah tangga maupun limbah industri. Rumah tangga dan industri adalah sumber utama limbah organik dan merupakan penyebab utama tingginya BOD (Bapedal 2002).

COD merupakan salah satu parameter indikator pencemar di dalam air yang disebabkan oleh limbah organik. COD adalah jumlah oksigen yang dibutuhkan untuk mengoksidasi zat organik yang ada dalam air dengan menggunakan oksidator kalium dikromat. Keberadaan COD di lingkungan sangat ditentukan oleh limbah organik, baik yang berasal dari limbah rumah tangga dan industri (Bapedal 2002).

\subsection{Daya tampung beban pencemaran}

Menurut Keputusan Menteri Lingkungan Hidup No 110 Tahun 2003 bahwa daya tampung beban pencemaran adalah kemampuan air pada suatu sumber air untuk menerima masukan beban pencemaran tanpa mengakibatkan air tesebut menjadi tercemar. Beban pencemaran ialah jumlah suatu unsur pencemar yang 
terkandung dalam air atau air limbah yang dinyatakan dalam satuan massa per waktu. Daya tampung adalah kemampuan lingkungan hidup untuk menyerap zat, energi dan atau komponen lain yang masuk atau dimasukkan ke dalamnya. (Soemarwoto 1997). Salah satu metode yang dapat digunakan untuk menentukan daya tampung beban pencemaran sungai adalah dengan metode Qual2Kw. Metode ini merupakan pengembangan dari Qual2 oleh United States Environmental Protection Agency (US EPA). Pengembangan metode Qual2 adalah Qual2E dan revisi yang terakhirnya Qual2Kw. Metode ini dapat mensimulasikan atau memprediksi perubahan kualitas sungai dari daerah hulu sampai hilir jika aliran limbah cair dikurangi ataupun ditambah. Dengan demikian dapat mengetahui daya tampung beban pencemaran sungai sesuai dengan kriteria baku mutu lingkungan yang telah ditetapkan (Sabar 2009).

\section{METODOLOGI}

\subsection{Jenis penelitian}

Penelitian bersifat dekriptif kualitatif yang menggambarkan kondisi perubahan kualitas air Sungai Batang Lembang dari daerah hulu (upstream) sampai hilir (downstream) pada kondisi eksisting/saat ini.

\subsection{Lokasi dan sampel}

\subsubsection{Lokasi}

Lokasi dari penelitian ini adalah air Sungai Batang Lembang segmen Kota Solok yang melintasi Kecamatan Lubuk Sikarah dan Kecamatan Tanjung Harapan.

\subsubsection{Sampel}

Lokasi pengambilan sampel penelitian ini pada perwakilan pengunaan lahan yang berada di sepanjang sungai Batang Lembang sebanyak 15 lokasi (Tabel 1). Lokasi pengambilan sampel dilakukan secara duplo menggunakan Aplikasi Geographical Information System (GIS) dan alat Global Positioning System (GPS). Lokasi pengambilan sampel dibagi atas beberapa ruas yang menggambarkan jarak pengambilan sampel dari hulu ke hilir. Parameter penentuan kualitas air sungai Batang Lembang mengacu pada Peraturan Pemerintah Nomor 82 Tahun 2001 seperti yang tertera pada Tabel 2.

Teknik pengambilan sampel yang dipilih adalah grab sampling, pengambilan sampel dilakukan sebanyak satu kali untuk tiap titik sampling, dengan ketentuan sampel diambil pada jarak $+1 / 3$ dan $2 / 3$ lebar sungai pada kedalaman $+1 / 2$ meter dari permukaan air sungai (Syahrul 2006). 
Tabel 1. Lokasi pengambilan sampel air sungai Batang Lembang, Kota Solok.

\begin{tabular}{|c|c|c|c|}
\hline No & Lokasi & Penggunaan Lahan & Titik Koordinat \\
\hline \multirow[t]{2}{*}{1} & Kelurahan Aro IV Korong, & Pertanian lahan basah & LS 00॰16'15,271" \\
\hline & Kecamatan Lubuk Sikarah & $\begin{array}{l}\text { berupa sawah dan lahan } \\
\text { kering berupa kebun } \\
\text { palawija dan holtikultura }\end{array}$ & BT $100^{\circ} 36^{\prime} 23,422^{\prime \prime}$ \\
\hline \multirow[t]{2}{*}{2.} & Kelurahan IX Korong, & pertanian lahan basah dan & LS $00^{\circ} 15^{\prime} 2,251^{\prime \prime}$ \\
\hline & $\begin{array}{l}\text { Kecamatan Lubuk Sikarah } \\
\text { Kota Solok. }\end{array}$ & pemukiman. & BT $100^{\circ} 36^{\prime} 59,444^{\prime \prime}$ \\
\hline \multirow[t]{2}{*}{3.} & Kelurahan Kampai Tugu & Pemukiman, industri rumah & LS $00^{\circ} 13^{\prime} 54,498^{\prime \prime}$ \\
\hline & $\begin{array}{l}\text { Karambia, Kecamatan Lubuk } \\
\text { Sikarah Kota Solok }\end{array}$ & $\begin{array}{l}\text { tangga dan pertanian lahan } \\
\text { basah dan lahan kering. }\end{array}$ & BT $100^{\circ} 37^{\prime} 43,25^{\prime \prime}$ \\
\hline \multirow[t]{2}{*}{4.} & Kelurahan Sinapa Piliang, & Pertanian lahan basah dan & LS 00॰12'53,705”' \\
\hline & $\begin{array}{l}\text { Kecamatan Lubuk Sikarah } \\
\text { Kota Solok. }\end{array}$ & $\begin{array}{l}\text { lahan kering berupa palawija } \\
\text { dan holtikultura. }\end{array}$ & BT 100³8'51,828” \\
\hline \multirow[t]{2}{*}{5.} & Kelurahan Tanah Garam, & Pemukiman, pertanian lahan & LS $00^{\circ} 12^{\prime} 25,454^{\prime \prime}$ \\
\hline & $\begin{array}{l}\text { Kecamatan Lubuk Sikarah, } \\
\text { Kota Solok }\end{array}$ & $\begin{array}{l}\text { basah dan lahan kering } \\
\text { berupa palawija dan } \\
\text { holtikultura }\end{array}$ & BT $100^{\circ} 40^{\prime} 6,05^{\prime \prime}$ \\
\hline \multirow[t]{2}{*}{6.} & Kelurahan VI Suku, & Pertanian lahan basah dan & LS $00^{\circ} 11^{\prime} 50,684^{\prime \prime}$ \\
\hline & $\begin{array}{l}\text { Kecamatan Lubuk Sikarah, } \\
\text { Kota Solok }\end{array}$ & $\begin{array}{l}\text { lahan kering berupa palawija } \\
\text { dan holtikultura. }\end{array}$ & BT $100^{\circ} 40^{\prime} 39,194 ”$ \\
\hline \multirow[t]{3}{*}{7} & Kelurahan Kampung Jawa, & Pemukiman dan pertanian & LS $00^{\circ} 47^{\prime} 11,6^{\prime \prime}$ \\
\hline & Kecamatan Tanjung & lahan basah dan lahan & BT 100³9'11,6” \\
\hline & Harapan Kota Solok. & kering. & \\
\hline \multirow[t]{3}{*}{8} & Kelurahan Koto Panjang, & Pemukiman dan pertanian & LS $00^{\circ} 47^{\prime} 31,2^{\prime \prime}$ \\
\hline & Kecamatan Tanjung & lahan basah dan lahan & BT $100^{\circ} 39^{\prime} 22,4^{\prime \prime}$ \\
\hline & Harapan, Kota Solok & kering. & \\
\hline \multirow[t]{3}{*}{9} & Kelurahan Nan Balimo, & Pemukiman dan pertanian & LS $00^{\circ} 46^{\prime} 12,2^{\prime \prime}$ \\
\hline & Kecamatan Tanjung & lahan basah dan lahan & BT $100^{\circ} 39^{\prime} 11,3 "$ \\
\hline & Harapan, Kota Solok. & kering & \\
\hline
\end{tabular}

Tabel 2. Parameter kualitas air berdasarkan Peraturan Pemerintah Nomor 82/2001.

\begin{tabular}{lllll}
\hline No & Parameter & Satuan & Metode & SNI \\
\hline 1 & TSS & $\mathrm{mg} / \mathrm{L}$ & Gravimetrik & $06-6989.3-2004$ \\
2 & BOD & $\mathrm{mg} / \mathrm{L}$ & Inkubasi, Titrimetrik & $6989.72: 2009$ \\
3 & COD & $\mathrm{mg} / \mathrm{L}$ & Reflux & $6989.2: 2009$ \\
\hline
\end{tabular}

\subsection{Teknik Pengumpulan Data}

Data sekunder yang diperlukan dalam penelitian kajian kualitas air dan penetapan daya tampung Sungai Batang Lembang diantaranya ialah:

- Data kualitas air Sungai Batang Lembang yang diperoleh dari hasil pemantauan dari pemerintah daerah Kota Solok;

- Jumlah masyarakat yang berada di sepanjang daerah aliran sungai (DAS) Batang Lembang yang diperoleh dari Rencana Tata Ruang Wilayah (RTRW) Kota Solok dan data dari SLHD Kota Solok; 
- Penggunaan lahan di sepanjang DAS Batang Lembang. Data ini diperoleh dari RTRW Kota Solok dan data dari Status Lingkungan Hidup Daerah (SLHD) Kota Solok;

- Batas administrasi mencakup wilayah yang dilalui oleh Sungai Batang Lembang;

- Kegiatan masyarakat di sepanjang aliran sungai yang menghasilkan limbah cair baik yang bersifat point source dan non-point source. Data ini diperoleh dari hasil survey lapangan.

Data primer yang dibutuhkan dalam kajian kualitas air dan penetapan daya tampung Sungai Batang Lembang ini , yaitu:

- Debit air sungai

- Temperatur udara

- Elevasi dan koordinat titik pengambilan sampel

- Lebar sungai

- Data kualitas air Sungai Batang Lembang

- Data Terkait Sumber Pencemar

Perolehan data sumber pencemar dilakukan menggunakan metode Focus Group Discussion (FGD). Kegiatan ini dilakukan di masing-masing kecamatan yang dialiri Sungai Batang Lembang.

\subsection{Teknik Analisis Data}

Analisis data terhadap kualitas air Sungai Batang Lembang mengacu pada Peraturan Pemerintah Nomor 82 Tahun 2001 tentang Pengendalian Kualitas air dan Pengelolaan Pencemaran Air. Peraturan ini digunakan untuk membandingkan kualitas sungai berdasarkan hasil uji laboratorium dengan baku mutu lingkungan Peraturan Pemerintah Nomor 82 Tahun 2001.

Penetapan daya tampung beban pencemaran Sungai Batang Lembang berpijak pada hasil analisis kualitas air Sungai Batang Lembang. Daya tampung sungai ditetapkan berdasarkan Keputusan Menteri Negara Lingkungan Hidup Nomor 110 Tahun 2003 yaitu dengan menggunakan aplikasi Qual2Kw.

Data Sumber Pencemar yang diperoleh dari hasil FGD berupa data kualitatif yang memuat tentang (1) aktivitas masyarakat yang menimbulkan terjadi pencemaran Sungai Batang Lembang dan (2) alternatif solusi yang diusulkan akan dianalisis dengan menggunakan teknik analisis data kualitatif yang merujuk pada Metode Spradley, yaitu:

- Pengumpulan data

- Reduksi Data

- Penyajian Data

- Penarikan kesimpulan secara induktif 


\section{HASIL DAN PEMBAHASAN}

\subsection{Gambaran Umum Lokasi Penelitian}

Secara geografis, Kota Solok terletak antara 00 $44^{\prime 2} 28^{\prime \prime}-00^{0} 49^{\prime} 12^{\prime \prime}$ LS dan $100^{0} 32^{\prime} 42^{\prime \prime}-100^{0} 41^{\prime} 42^{\prime \prime}$ BT. Luas Kota Solok adalah $5764 \mathrm{Ha}$ atau 57,64 km² yang terdiri atas 2 (dua) kecamatan, yaitu (1) Kecamatan Lubuk Sikarah dan (2) Kecamatan Tanjung Harapan. Luas wilayah Kecamatan ialah 3500 Ha dengan 7 (tujuh) kelurahan dan Kecamatan Tanjung Harapan seluas 2264 Ha dengan 6 (enam) kelurahan (BPS 2013).

Kota Solok berada pada ketinggian 390 meter di atas permukaan laut (mdpl). Kota Solok memiliki topografi berupa dataran dan perbukitan. Adapun daerah datar dengan kelerengan $0-2 \%$ seluas 784,51 Ha (13,61\%) yang tersebar di pusat kota dan daerah datar dengan kelerengan 2-8\% seluas 1.875,38 $\mathrm{Ha}$ $(32,54 \%)$ yang tersebar di bagian Selatan dan utara kota. Daerah datar tersebut potensial untuk kawasan permukiman dan budidaya lainnya (BPS 2013).

Sungai-sungai utama yang terdapat di Kota Solok adalah Batang Lembang, Batang Gawan, dan Batang Air Binguang. Sungai-sungai tersebut memiliki batas hidrologi yang mencakup wilayah Kota Solok dan Kabupaten Solok. Tentang spesifikasi ke 3 (tiga) sungai ini, disajikan pada Tabel 3.

Tabel 3. Nama dan panjang sungai di Kota Solok.

\begin{tabular}{cccccccc}
\hline \multirow{2}{*}{ No } & $\begin{array}{llcl}\text { Sungai } \\
\text { Utama }\end{array}$ & $\begin{array}{c}\text { Panjang } \\
(\mathrm{m})\end{array}$ & \multicolumn{2}{c}{ Lebar $(\mathrm{m})$} & \multicolumn{2}{c}{ Kedalaman } & \multicolumn{2}{c}{ Debit $\left(\mathrm{m}^{3} / \mathrm{dtk}\right)$} \\
& Permukaan & Dasar & Maks & Min \\
\hline 1 & $\begin{array}{l}\text { Batang } \\
\text { Lembang }\end{array}$ & 9155 & 30 & 25 & 6 & 179,85 & 7,50 \\
2 & $\begin{array}{l}\text { Batang } \\
\text { Gawan }\end{array}$ & 3125 & 12 & 8 & 5 & 73,50 & 0,35 \\
3 & $\begin{array}{l}\text { Batang } \\
\text { Bingung }\end{array}$ & 2650 & 5 & 3 & 4 & 14,40 & - \\
\hline
\end{tabular}

Jumlah penduduk Kota Solok mengalami kenaikan dengan laju pertumbuhan penduduk sebesar 2,13\%. Pada tahun tahun 2013 jumlah penduduk terbanyak terdapat di Kelurahan Tanah Garam Kecamatan Lubuk Sikarah sebanyak 12.799 jiwa, sedangkan yang terkecil terdapat di Kelurahan Laing Kecamatan Tanjung Harapan yaitu sebanyak 1.146 jiwa.

Hasil penelitian berupa identifikasi terhadap Daerah Aliran Sungai (DAS) Batang Lembang diperoleh bahwa sumber kegiatan yang berpotensi sebagai sumber pencemar pada umumnya berasal dari limbah pemukiman penduduk, aktivitas ekonomi di sektor pertanian, industri seperti pabrik tahu, rumah makan, usaha katering, bengkel, pencucian mobil/motor, peternakan ayam, dan galian $\mathrm{C}$ serta pasar tradisional. Identifikasi kegiatan yang menjadi sumber pencemar Sungai Batang Lembang dikelompokkan menjadi 3 (tiga) daerah yaitu kawasan hulu, tengah dan hilir. Daerah hulu berada di Kecamatan Tanjung Harapan yakni pada Kelurahan Nan Balimo. Daerah tengah berada pada 
Kelurahan VI Suku, Kecamatan Lubuk Sikarah, sedangkan daerah hilir berada di Kelurahan Aro IV Korong, Kecamatan Lubuk Sikarah. Identifikasi pencemar diperoleh melalui observasi dan FGD serta studi literatur berdasarkan pola Penggunaan lahan pada wilayah Daerah Aliran Sungai (DAS). Identifikasi ini, menunjukkan penyebaran tata guna lahan yang ada pada kawasan.

Daerah hulu Sungai Batang Lembang sesuai dengan pola penggunaan lahan dan struktur dan karakteristik demografi, maka dapat diidentifikasi bahwa sumber pencemar yang tertinggi pada kawasan ini adalah (1) aktivitas ekonomi masyarakat di sektor pertanian, berupa sawah, (2) ladang campuran dan (3) aktivitas sektor peternakan berupa peternakan ayam serta (4) kegiatan masyarakat di perkebunan campuran.

Daerah tengah Sungai Batang Lembang sesuai dengan pola penggunaan lahan dan struktur dan karakteristik demografi, maka dapat diidentifikasi bahwa sumber pencemar yang tertinggi pada kawasan ini adalah (1) aktivitas rumah tangga/limbah domestik (2) pasar, rumah potong hewan, industri (3) sektor pertanian Sawah.

Daerah hilir Sungai Batang Lembang sesuai dengan pola penggunaan lahan dan struktur dan karakteristik demografi, maka dapat diidentifikasi bahwa sumber pencemar yang tertinggi pada kawasan ini adalah (1) aktivitas ekonomi di sektor pertanian berupa Sawah, (2) aktivitas rumah tangga berupa limbah (3) kegiatan masyarakat di perkebunan campuran. Hasil identifikasi sumber pencemaran berdasarkan daerah hulu dan tengah.

\subsection{Daya Tampung Beban Pencemaran Sungai Batang Lembang}

\subsubsection{Parameter TSS}

Hasil perhitungan daya tampung beban pencemaran Sungai Batang Lembang segmen Kota Solok terhadap parameter TSS, dapat dilihat pada grafik berikut (Gambar 1). Hasil penelitian dengan menggunakan metode Qual2Kw dalam hal pemodelan parameter dapat dibaca pada Gambar1, untuk TSS Model air sungai akan mengalami proses self purification, karena tanpa ada sumber pencemar, air sungai dapat terdegradasi atau terurai secara sendirinya, sedangkan pada TSS Model observasi, secara keseluruhan melampaui TSS Model Baku Mutu TSS Kelas II sesuai PP. 82 Tahun 2001 yakni sebesar 50 mg/L. Dilihat dari grafik TSS pada ruas 1, 2, 4, 5, 6, 7, 9, 10, 13, 15 (digambarkan dengan titik pada grafik) harus dikurangi beban pencemarannya sebesar $5.832,00 \mathrm{Kg} / \mathrm{hari}$ (ruas 1), 2.527,20 Kg/hari (ruas 2), 11.437,20 Kg/hari (ruas 4), 1.425,60 Kg/hari (ruas 5), 5.378,40 Kg/hari (ruas 6), 4.082,40 Kg/hari (ruas 7), 23.490,00 Kg/hari (ruas 9), 5.248,80 Kg/hari (ruas 10), 12.979,44 Kg/hari (ruas 13) dan 6.486,48 $\mathrm{Kg} /$ hari (ruas 15); Hal ini karena adanya (1) aktivitas ekonomi masyarakat di sektor pertanian, berupa sawah yang langsung berdekatan dengan sungai Batang Lembang yang bisa mengakibatkan terjadinya erosi, (2) aktivitas sektor 
peternakan berupa peternakan ayam, yakni masyarakat langsung membuang sisa-sisa pakan ayam langsung ke sungai sehingga, bisa meningkatkan beban pencemaran TSS.

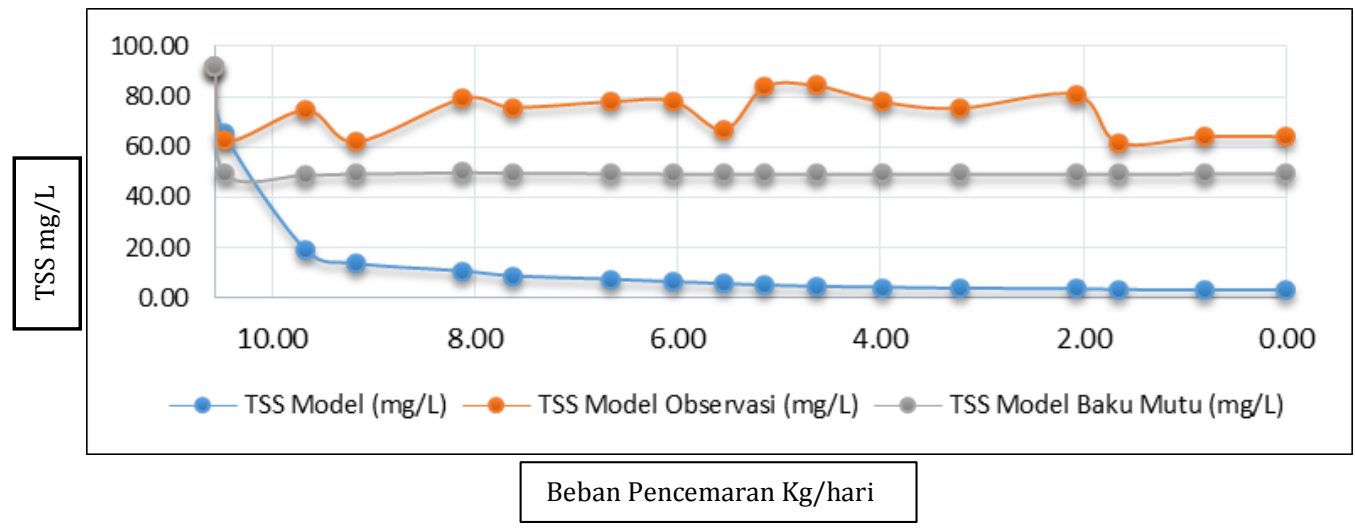

Gambar 1. Hasil Perhitungan Model Qual2Kw Parameter TSS.

Berdasarkan hasil penelitian ini jika dibandingkan dengan beberapa hasil penelitian yang relevan dapat dilihat bahwa pada Sungai Batang Lembang segmen Kota Solok untuk TSS dipengaruhi oleh aktivitas ekonomi masyarakat di sektor pertanian berupa sawah yang langsung berdekatan dengan sungai yang bisa mengakibatkan terjadinya erosi, aktivitas peternakan ayam. Pada Sungai Metro dipengaruhi karena banyaknya alih fungsi lahan menjadi daerah terbangun/pemukiman disekitar aliran sungai, sehingga menyebabkan padatan - padatan tanah yang memasuki aliran sungai, melalui run off semakin meningkat (Azwar 2013), sedangkan pada Sungai Batang Hari dipengaruhi karena adanya aktivitas penambangan emas tanpa izin (PETI). Aktivitas PETI dilakukan dengan mengeruk atau menyedot sedimen di dasar sungai yang dapat menyebabkan meningkatnya kandungan TSS di perairan sungai (Zuchri 2011).

\subsubsection{Parameter BOD}

Hasil perhitungan daya tampung beban pencemaran Sungai terhadap BOD dapat dilihat pada Gambar 2. Hasil penelitian dengan menggunakan metode Qual2Kw dalam hal pemodelan BOD dapat dibaca pada Gambar 2. Untuk BOD Model, air sungai mengalami proses self purification, karena tanpa ada sumber pencemar air sungai dapat terdegradasi atau terurai secara sendirinya, sedangkan pada BOD Model observasi pada ruas 1, 2, 3 dan 4 melampaui BOD Model Baku Mutu sebesar 3,90 mg/L > 2,91 mg/L (ruas 1), 3,53 mg/L > 2,92 $\mathrm{mg} / \mathrm{L}$ (ruas 2), 3,98 mg/L > 2,84 mg/L (ruas 3) dan $3.01 \mathrm{mg} / \mathrm{L}>2,86 \mathrm{mg} / \mathrm{L}$ (ruas $3)$. 


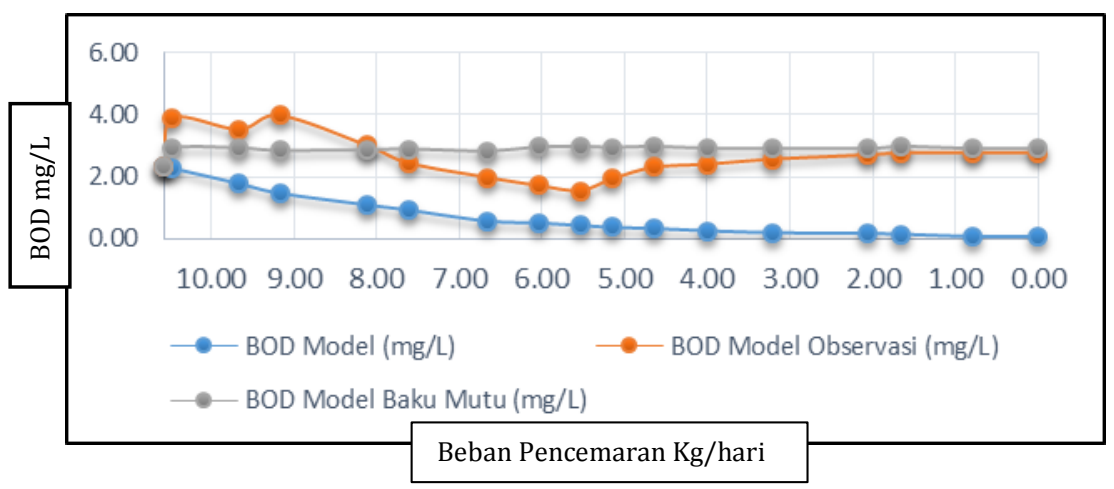

Gambar 2. Hasil Perhitungan Model Qual2Kw Parameter BOD

Berdasarkan Gambar 3 BOD pada ruas 1, 3, 9, 10, 11, 12, 13 dan ruas 15 harus dikurangi beban pencemarannya sebesar 453,60 Kg/hari (ruas 1), 336,96 $\mathrm{Kg} / \mathrm{hari}$ (ruas 3), 324,00 Kg/hari (ruas 9), 324,00 Kg/hari (ruas 10), 129,60 $\mathrm{Kg} / \mathrm{hari}$ (ruas 11), 194,40 Kg/hari (ruas 12), 207,36 Kg/hari (ruas 13) dan 77,76 $\mathrm{Kg} / \mathrm{hari}$ (ruas 15)

Hal ini disebabkan pada ruas ini sumber pencemar sangat tinggi seperti: (1) aktivitas rumah tangga/limbah domestik, industri (2) pasar, rumah potong hewan serta (3) sektor pertanian Sawah. Penelitian Zul (2011) pada sungai Batang Kuranji, beban pencemaran untuk BOD pada km 15,75 - km 9,75 (Sungai Limau Manis s/d Jembatan Kalumbuk) telah melebihi ambang batas daya tampung sebesar 299,5 kg/dtk dari target beban pencemaran sebesar 54,6 kg/dtk. Pada km 9,75 - km 6 (Jembatan Kalumbuk s/d Intake PDAM) dan km 6 $\mathrm{km} 1,5$ (Intake PDAM s/d Batang Guo) telah melebihi sebesar 557,80 kg/dtk dari total beban pencemaran yang ditargetkan sebesar 218,40 kg/dtk, sumber pencemar Sungai Batang Kuranji ini berasal dari limbah domestik tanpa adanya treatment, disamping itu juga disebabkan adanya aktifitas pertanian, pabrik tahu, perbengkelan dan pasar, sedangkan hasil pemantauan BOD di Sungai Metro Kota Malang oleh Azwar (2013), menunjukkan terjadinya peningkatan dari stasiun 1 ke stasiun 3. Nilai BOD pada stasiun 1 sebesar $4,7 \mathrm{mg} / \mathrm{L}$, stasiun 2 sebesar $6,1 \mathrm{mg} / \mathrm{L}$ dan pada stasiun 3 sebesar $6,25 \mathrm{mg} / \mathrm{L}$. Naiknya BOD dapat berasal dari bahan-bahan organik yang berasal dari limbah domestik dan pertanian.

Hasil penelitian ini jika dibandingkan dengan beberapa hasil penelitian yang relevan dapat dilihat bahwa pada sungai Batang Lembang segmen Kota Solok untuk BOD dipengaruhi dengan adanya aktifitas rumah tangga/limbah domestik, industri, pasar, rumah potong hewan serta sektor pertanian Sawah. Naiknya BOD pada Sungai Metro dapat berasal dari bahan-bahan organik yang berasal dari limbah domestik dan pertanian (Azwar 2013), sedangkan pada sungai Batang Kuranji tingginya BOD berasal dari imbah domestik, disamping itu 
juga disebabkan adanya aktifitas pertanian, pabrik tahu, perbengkelan dan pasar (Zul 2011).

\subsubsection{Parameter COD}

Hasil perhitungan daya tampung beban pencemaran terhadap COD disampaikan pada Gambar 3.

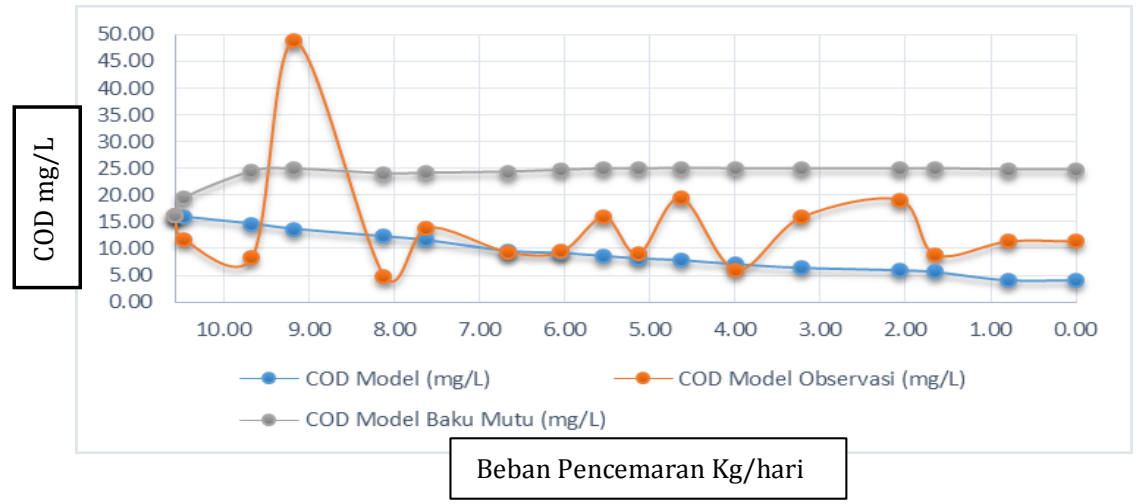

Gambar 3. Hasil Perhitungan Model Qual2Kw Parameter BOD.

Hasil penelitian COD Model air sungai mengalami proses self purification, karena tanpa ada sumber pencemar air sungai dapat terdegradasi atau terurai secara sendirinya, sedangkan untuk COD Model observasi dari semua titik sampel tidak ada yang melampaui COD Model Baku Mutu, kecuali pada ruas 3 sebesar 48,81 mg/L > 24,87 mg/L (ruas 3).

Dilihat pada Gambar 3 COD pada ruas 3, 5, 8, 10, 12, 13 dan ruas 15 harus dikurangi beban pencemarannya sebesar $16.264,80 \mathrm{Kg} /$ hari (ruas 3), 3.888,00 $\mathrm{Kg} / \mathrm{hari}$ (ruas 5), 4.879,44 Kg/hari (ruas 8), 12.214,80 Kg/hari (ruas 10), $13.504,32 \mathrm{Kg} / \mathrm{hari}$ (ruas 12), 4.451,76 Kg/hari (ruas 13) dan 3.039,12 Kg/hari (ruas 15).

Hal ini disebabkan masih banyak kawasan pertanian, perkebunan dan peternakan sehingga sumber pencemar yang banyak masuk ke sungai Batang Lembang berasal dari kimia organik. Air sungai Batang Lembang masih bisa menerima beban pencemaran, untuk COD pendekatannya lebih kepada kimia anorganik dan senyawa kimia anorganik ini banyak pada pembuangan limbah cair pada Perusahaan/Industri.

Dalam penelitian Zul Adri (2011), daya tampung beban pencemaran COD sungai Batang Kuranji untuk daerah hilir (down stream) parameter COD telah kelebihan beban pencemaran sebesar $413 \mathrm{~kg} / \mathrm{dtk}$ dari target yang ditetapkan sebesar $2.470 \mathrm{~kg} / \mathrm{dtk}$. Hal ini disebabkan pada daerah ini ada masuk sumber pencemar seperti limbah bengkel, limbah permukiman dan limbah hotel, sedangkan hasil pemantauan COD di Sungai Metro Kota Malang, menunjukkan terjadinya peningkatan dari stasiun 1 ke stasiun 3. COD pada stasiun 1 sebesar 
11,11 mg/L, pada stasiun 2 sebesar 15,97 mg/L dan pada stasiun 3 sebesar 17,56 mg/L. COD yang tinggi, mengindikasikan semakin besar tingkat pencemaran yang terjadi, peningkatan COD air Sungai Metro disebabkan oleh pembuangan limbah yang bersumber dari daerah terbangun/pemukiman dan daerah pertanian yang berada di sekitar sungai. (Azwar 2013).

Hasil penelitian ini jika dibandingkan dengan beberapa hasil penelitian yang relevan dapat dilihat bahwa pada sungai Batang Lembang segmen Kota Solok untuk COD dipengaruhi dengan adanya pembuangan limbah cair pada perusahaan/industri. Naiknya COD pada sungai Batang Kuranji disebabkan pada daerah ini ada masuk sumber pencemar seperti limbah bengkel, limbah permukiman dan limbah hotel (Zul 2011), sedangkan peningkatan COD pada Sungai Metro disebabkan oleh pembuangan limbah yang bersumber dari daerah terbangun/permukiman dan daerah yang berada di sekitar sungai (Azwar 2013).

\section{KESIMPULAN DAN SARAN}

Berdasarkan hasil penelitian, mengenai daya tampung beban pencemaran Sungai Batang Lembang segmen Kota Solok dapat disimpulkan Total Suspended Solid (TSS) dari hulu sampai ke hilir pada ruas 1, 2, 4, 5, 6, 7, 9, 10, 13, 15 harus dikurangi beban pencemarannya sebesar $5.832,00 \mathrm{Kg} /$ hari (ruas 1), 2.527,20 $\mathrm{Kg} /$ hari (ruas 2), 11.437,20 Kg/hari (ruas 4), 1.425,60 Kg/hari (ruas 5), 5,378,40 $\mathrm{Kg} / \mathrm{hari}$ (ruas 6), 4.082,40 Kg/hari (ruas 7), 23.490,00 Kg/hari (ruas 9), 5.248,80 $\mathrm{Kg} / \mathrm{hari}$ (ruas 10), 12.979,44 Kg/hari (ruas 13) dan 6.486,48 Kg/hari (ruas 15).

Parameter BOD pada ruas 1, 3, 9,10,11,12,13 dan ruas 15 harus dikurangi beban pencemarannya sebesar 453,60 Kg/hari (ruas 1), 336,96 Kg/hari (ruas 3), $324,00 \mathrm{Kg} / \mathrm{hari}$ (ruas 9), 324,00 Kg/hari (ruas 10), 129,60 Kg/hari (ruas 11), $194,40 \mathrm{Kg} / \mathrm{hari}$ (ruas 12), 207,36 Kg/hari (ruas 13) dan 77,76 Kg/hari (ruas 15).

Parameter COD pada ruas $3,5,8,10,12,13$ dan ruas 15 harus dikurangi beban pencemarannya sebesar $16.264,80 \mathrm{Kg} / \mathrm{hari}$ (ruas 3), 3.888,00 Kg/hari (ruas 5), 4.879,44 Kg/hari (ruas 8), 12.214,80 Kg/hari (ruas 10), 13.504,32 $\mathrm{Kg} / \mathrm{hari}$ (ruas 12), 4.451,76 Kg/hari (ruas 13) dan 3.039,12 Kg/hari (ruas 15).

Disarankan pada kawasan Kelurahan Nan Balimo, agar tidak terlalu dekat dengan badan sungai karena akan mengakibatkan erosi dan untuk sektor peternakan agar tidak membuang sisa makanan ke badan sungai. Disarankan pada kawasan VI suku dan Tanah Garan yang pemukimannya padat penduduk agar dibuatkan IPAL Komunal dan bagi industri agar mengolah limbahnya sebelum masuk ke badan sungai. Perlu penentuan daya tampung sungai secara berkala di setiap tahapan implementasi program pembangunan. 


\section{Daftar Pustaka}

Azwar A. 2013. Kajian kualitas air dan status mutu air sungai Metro di Kecamatan Sukun Kota Malang. Jurnal Bumi Lestari 13(2).

[BPS] Badan Pusat Statistik. 2013. Sumatera Barat dalam angka. BPS Provinsi Sumatera Barat.

[BPS] Badan Pusat Statistik. 2013. Solok dalam angka. Badan Pusat Statitsitik (BPS) Kota Solok.

[Bapedal] Badan Pengendalian Dampak Lingkungan Menteri Negara Lingkungan Hidup. 2002. Analisis kualitas air dan limbah cair.

Keputusan Menteri Lingkungan Hidup Nomor 110 Tahun 2003 tentang Pedoman penetapan daya tampung beban pencemaran air pada sumber air.

Kristanto P. 2002. Ekologi industri. ANDI Yogyakarta. Yogyakarta.

Peraturan Pemerintah Nomor 82 Tahun 2001 tentang Pengelolaan dan Kualitas Air dan Pengendalian Pencemaran Air.

Sabar G. 2009. Daya tampung sungai Kampar. KNLH-PPLH Regional Sumatera

Soemarwoto 0. 1997. Ekologi, lingkungan hidup dan pembangunan. Djambatan. Jakarta.

Syahrul J. 2006. Teknik pengambilan sampel dan penanganan sampel. KLH PPLH Regional Sumatera. Riau.

Zuchri A. 2011. Kajian daya tampung beban pencemaran Sungai Batanghari pada Penggal Gasiang-Sungai Langkok Provinsi Sumatera Barat.

Zul A. 2011. Kajian kualitas air dan daya tampung beban pencemaran sungai Batang Kuranji [Tesis]. Magister Ilmu Lingkungan. Universitas Negeri Padang. Padang. 